\section{ENTRE SÁBIO E SOBERANO: ASPECTOS TEMÁTICOS, DIEGÉTICOS E COMPOSICIONAIS NO ROMANCE DE ALEXANDRE}

\author{
Pedro Ipiranga Júnior* \\ Recebido em: 02/03/2020 \\ Aprovado em: 26/03/2020
}

RESUMO: Agrupando relato histórico, gênero epistolar, narrativa de maravilhas, trechos em prosímetro com mistura de prosa e verso, incorporando conjuntos textuais de outras obras, o Romance de Alexandre não deixa de assimilar em sua dinâmica romanesca não apenas outros gêneros de discursos, como também mimetiza os processos do fazer narrativo. Nesse trabalho tenho como propósito analisar formas de marcação narrativa no $R A$ que digam respeito a aspectos temáticos, diegéticos ou composicionais, enfocados a partir de dois enquadramentos: a) estejam vinculados aos discursos e às ações de Alexandre e expressem algum tipo de princípio filosófico, em geral, ou ético, em particular; b) indiquem a assimilação, aproximação ou apropriação por parte do protagonista de características de determinados deuses ou heróis, mormente de Héracles, Dioniso e Amon, por um lado, e de personagens históricos ou fictícios, por outro, a exemplo de Sesóstris ou Sesôncosis, Semíramis e Aquiles. Em função disso, analisarei trechos da recensão $\alpha$ e, mais restritivamente, da recensão $\beta$, especificamente com a variante representada pelo manuscrito L. Pretende-se com esse levantamento e comparação verificar se essas referências constituem uma rede de sinalizações interconectadas e, consequentemente, uma forma peculiar de garantir certa forma de unidade peculiar para obra, a despeito da possibilidade de agrupar novos materiais e outros conjuntos textuais.

PALAVRAS-CHAVE: Romance de Alexandre; romance antigo; gênero Bíos; literatura sapiencial.

BETWEEN WISE AND SOVEREIGN: THEMATIC, DIEGETIC AND COMPOSITIONAL ASPECTS IN ALEXANDER ROMANCE
* Professor Associado, Departamento de Polonês, Alemão e Letras Clássicas, Universidade Federal do Paraná.

junioripiranga7@hotmail.com

(ic) \title{
.
}


ABSTRACT: Grouping historical report, epistolary genre, narrative of wonders, extracts in prosimeter with a mixture of prose and verse, incorporating textual sets from other works, the Alexander Romance does not fail to assimilate in his novelistic dynamics not only other genres of discourses, such as it also mimics the processes of narrative making. In this work, I aim to analyze forms of narrative marking in the $A R$ that concern thematic, diegetic or compositional aspects, focused on two frameworks: a) are linked to Alexandre's speeches and actions and express some kind of philosophical principle, in general, or ethical, in particular; b) indicate the protagonist's assimilation, approximation or appropriation of characteristics of certain gods or heroes, especially Heracles, Dionysus and Ammon, on the one hand, and historical or fictional characters, on the other, such as Sesostris or Sesoncosis, Semiramis and Achilles. As a result, I will analyze excerpts from the $\alpha$ recension and, more restrictively, the $\beta$ recension, specifically with the variant represented by the manuscript L. This survey and comparison are intended to verify whether these references constitute a network of interconnected signals and, consequently, a peculiar shape to guarantee a certain form of unity peculiar to the work, despite the possibility of grouping new materials and other textual sets.

KEYWORDS: Alexander Romance; ancient novel; genre of Bios; sapiential literature.

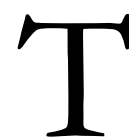

endo atraído nos últimos anos a atenção reiterada da crítica especializada, a obra mais conhecida como Romance de Alexandre se apresenta como um texto polimórfico, cujas recensões ou versões na Antiguidade e no período medieval retrabalham, adaptam, alteram, acrescentam e/ou agrupam partes diversas (por vezes, heteróclitas) e de extensões variadas aos conjuntos textuais referentes às formas mais antigas do texto. Por seu turno, bem antes da composição e formação do romance ou de suas variantes, os relatos e lendas sobre Alexandre já circulavam antes de sua morte em 323 a.C. na Babilônia. Aristóbulo, Ptolomeu (que se tornariam as fontes principais de Arriano) e Calístenes, por um lado, e Clitarco, Onesícrito e Nearco, por outro, registraram por escrito as ações e campanhas de Alexandre, buscando, em maior ou menor medida, acompanhar a sequência de fatos pretensamente históricos ou reportando os elementos extraordinários e as mais incríveis narrativas de maravilhas. Ainda que se possa divisar no romance a influência mais acurada de determinadas fontes, é sobre esse fundo difuso e a partir de uma perspectiva múltipla de abordagem narrativa que o texto se constitui em suas variadas versões já na Antiguidade.

Embora boa parte dos críticos se inclinem para uma datação no séc. III d.C., alguns especialistas, cujo exemplo mais precípuo atualmente é o de Richard Stoneman, advogam a tese de uma datação helenística, se não no séc. III, pelo menos no séc. II a.C. De uma forma ou de outra, o romance teria assimilado, de maneira compilatória, ${ }^{1}$ textos de composição mais antiga que, segundo Merkelbach, abarcariam três componentes principais: uma fonte

\footnotetext{
${ }^{1}$ Para as características do caráter compilatório do texto associado ao conceito de literatura de consumo ou paraliteratura, cf. Gallo (2005, p. 47-8); Hansen (1998).
} 
histórica, uma coleção de cartas e relatos de maravilhas, aos quais se somariam mais duas outras seções: uma parte relativa à interlocução entre Alexandre e os brâmanes e outra que seria o relato dos últimos dias de Alexandre. Agrupando relato histórico, gênero epistolar, narrativa de maravilhas, trechos em prosímetro com mistura de prosa e verso, incorporando conjuntos textuais de outras obras, o Romance de Alexandre não deixa de exibir sua natureza gramatofágica, segundo a concepção de Jacyntho Lins Brandão, ou seja, assimila em sua dinâmica romanesca não apenas outros gêneros de discursos, como também mimetiza os processos do fazer narrativo. Por outro lado, o endereçamento da obra, cujo título nas diversas variantes inclui frequentemente o termo bios, a ressitua no campo do biográfico, o que resulta numa orientação de leitura tendente para a persona biográfica de Alexandre.

A literatura sapiencial, por sua vez, está representada no $R A^{2}$ não apenas pela incorporação de textos que, a exemplo do diálogo entre Alexandre e os chamados gimnosofistas indianos, apresentam uma perspectiva explícita de tal gênero, mas através de ditos, anedotas, formulações variadas de princípios éticos disseminados através de toda a narrativa, como também por meio da caracterização do personagem de Alexandre como interlocutor de sábios ou mesmo produtor de máximas, pensamentos, atitudes ou ações que revelam um engajamento em questões filosóficas. Em embates discursivos com seus rivais, como nas trocas de cartas entre ele e Dario e, depois, entre ele e Poro, Alexandre se sobressai tanto pela argumentação mais sagaz, quanto pela atitude de sensatez e modéstia contraposta à jactância e býbris dos adversários. Destaca-se na obra, segundo a perspectiva de Asirvatham (2012, p. 317-8), uma caracterização de Alexandre de caráter nitidamente cínico, ou mesmo um retrato cínico-estoico do protagonista, na esteira do advogado por Fisch (1937, p. 129-51) para a tradição mais geral sobre Alexandre nos períodos helenístico e romano.

Neste trabalho tenho como propósito analisar formas de marcação narrativa que digam respeito a aspectos temáticos, diegéticos ou composicionais, enfocados a partir de dois enquadramentos: a) que estejam vinculados aos discursos e às ações de Alexandre e expressem algum tipo de princípio filosófico, em geral, ou ético, em particular; b) que indiquem a assimilação, aproximação ou apropriação por parte do protagonista de características de determinados deuses ou heróis, mormente de Héracles, Dioniso e Amon, por um lado, e de personagens históricos ou fictícios, por outro, a exemplo de Sesóstris ou Sesôncosis, Semíramis, Aquiles. Em função disso, analisarei trechos da recensão $\alpha$ em cotejo com a recensão $\beta$, especialmente com a variante representada pelo manuscrito L. Pretendese com esse levantamento e comparação verificar se essas referências constituem uma rede de sinalizações interconectadas e, consequentemente, uma forma peculiar de garantir certa forma de unidade peculiar para a obra, a despeito da possibilidade de agrupar novos materiais e outros conjuntos textuais.

Como guia de várias das questões apontadas, vou utilizar as indicações e conclusões de Grammatiki Karla em seu artigo "Folk Narrative Techniques in the Alexander Romance". Também advogando uma unidade e uma composição literária para o $R A$, ela concentra sua

\footnotetext{
${ }^{2}$ Uso a sigla $\mathrm{R} A$, a partir de então, para Romance de Alexandre.
} 
análise em três aspectos: 1) os temas recorrente (leitmotives), 2) a retomada de motivos e tópicos em várias unidades narrativas e 3) dois esquemas discursivos básicos: a) o esquema ternário (um elemento ou aspecto é empregado três vezes) e b) o esquema de antítese. Quanto aos temas/motivos recorrentes, o protagonista é reiteradamente caracterizado

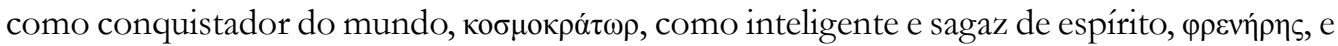
associado a dois semideuses, Héracles e Dioniso. No segundo aspecto, Karla explicita como os tópicos relativos ao personagem de Nectanebo, a magia e o disfarce, são refuncionalizados e empregados para o discurso e ações de Alexandre: ele tem o poder de persuadir os outros pelo encanto proporcionado por suas palavras, comparado em um dado momento a Orfeu, e se utiliza de disfarces, quando, por exemplo, vai disfarçado de mensageiro até Dario. Além disso, um embate típico, como entre Alexandre e Nicolau na primeira unidade narrativa, é retomado ulteriormente nos confrontos com Dario e com Poro, em que vários elementos são similares, mormente o contraste entre a moderação de Alexandre e a arrogância desdenhosa dos antagonistas. Por fim, como terceiro aspecto, ela chama a atenção para dois esquemas básicos que indicariam o emprego de fontes populares, empregando elementos característicos da estrutura dos contos. Como exemplos do esquema ternário ela elenca os seguintes: são três os presentes enviados por Dario a Alexandre (um chicote, uma bola e um cofre com ouro); três são os oradores a se manifestarem em Atenas (Ésquines, Dêmades e Demóstenes); três são os oráculos recebidos do sol e da lua referentes à morte de Alexandre; no palácio de Candace, dois filhos são favoráveis a Alexandre, enquanto o terceiro lhe é contrário; em relação a Héracles e a Dioniso, Alexandre é comparado como um terceiro termo. Relativamente ao esquema de antítese, há várias contraposições expostas ao longo da narrativa, como a prudência dos gregos versus a soberba dos bárbaros, ou o corpo diminuto de Alexandre em contraste com o corpo colossal de Poro, o rei indiano.

Segundo a ótica de Cizek (1978, p. 593-607), é possível, de forma similar, depreender do $R A$ padrões narrativos advindos de lendas e da cultura popular. Em função disso, a apropriação das fontes de relato histórico não seria, segundo ele, da ordem do aleatório, de uma pretensa ignorância ou incapacidade no manejo dos dados, mas estaria dentro de uma concepção estética que, a despeito das distorções históricas, primaria por um certo arranjo narrativo, em que se utilizaria da estrutura do conto popular, mas reformulada e adaptada por meio de elementos e formulações retóricos próprios do romance antigo. Como Karla, Cizek se vale da classificação de Propp sobre o conto popular para analisar três tipos de uma sequência formular refuncionalizada no $R A$ para três personagens importantes: Filipe, Dario e Alexandre. Desse modo, haveria o emprego de elementos similares nas cenas relativas às mortes de cada um dos três, dentro de uma perspectiva ético-estética que emprega uma matriz popular e, ao mesmo tempo, a reincorpora dentro da dinâmica romanesca que, para ele, se baseia num formalismo retórico. As três sequências consideradas por ele essenciais seriam: peripécias e aventuras concernentes 1) ao assassinato, 2) à vingança e 3) à coroação do herói. Enquanto em relação a Filipe e Dario, Alexandre seria responsável pela vingança e, consequentemente, receberia a coroa do reino macedônico e do império persa respectivamente, na morte do próprio protagonista, por seu turno, haveria elementos simétricos, mas Cizek parece encontrar dificuldade para encaixar a sequência da coroação: 
chega ele à conclusão de que a terceira sequência, relativa à coroação, adviria do fato de Alexandre ter escolhido seus sucessores entre os diádocos.

Em um estudo de 2016, Ioannis Konstantakos também verifica no $R A$ uma afiliação com a estrutura do conto popular. Analisando mais especificamente a sequência da troca de cartas entre Alexandre e Dario, ele divisa como base para este relato um padrão relativo ao concurso de metamorfose ou transformação mágica $\left(\mathrm{n}^{\circ} 325\right.$ no inventário estabelecido por Aarne, Thompson e Uther) entre dois adversários. Tomando exemplos da épica suméria, da novela egípcia e do Éxodo judaico, ele arrola algumas variantes importantes desse padrão que revela os seguintes elementos: cada competidor se metamorfoseia ou transforma algo de forma mágica; as transformações podem ser em animais, plantas, objetos ou elementos naturais, como fogo, trovão, tempestade; há um crescente nas manifestações, em que cada concorrente tenta superar o rival; o concurso termina pela morte ou impedimento daquele que se sai inferior no embate. Na comparação com o $\mathrm{R} A$, Konstantakos faz menção à passagem em que há a primeira troca de cartas entre Dario e Alexandre: depois de ter conquistado Tiro e ter adentrado na Ásia, Alexandre recebe de Dario a correspondência juntamente com três presentes: um chicote, uma bola e um cofre com ouro. Na carta, o rei persa explicita o sentido de cada um dos três; cito o passo em L na tradução de Laura Cohen Rabelo (2017, p. 43-4):

Rei dos reis e descendente dos deuses, emergente como o sol, eu, o próprio deus Dario, para Alexandre, meu servo. Comando e ordeno que você retorne para os seus parentes, que você seja meu escravo e que vá deitar no colo da sua mãe Olímpia. É a sua idade, você deve ser educado e criado. Por isso enviei a você um chicote, uma bola e uma caixa de ouro - pegue o que você quiser primeiro. O chicote é para mostrar que você ainda precisa ser educado, a bola é para você brincar como os da sua idade (e não vá persuadir, arrogante, os jovens desta idade, como um chefe de piratas, levando-os consigo para perturbar as cidades). Pois nem a reunião de todo o mundo habitado poderá derrubar o reinado persa. Enorme é a minha multidão de soldados, tão grande quanto alguém não pode contar grãos de areia, e tenho ouro e prata o bastante para preencher toda a terra. Também enviei a você uma caixa cheia de ouro, porque, como você não tem as provisões para dar aos seus companheiros, pode dar a eles o necessário para que cada um seja reenviado para a própria pátria. Se você não acreditar nas minhas ordens, eu vou te perseguir, você vai ser perseguido pelos meus generais, e você não vai ser educado como filho de Filipe, mas vai ser crucificado como um desertor. $(R A, 1.36)$

Em sua resposta a Dario, Alexandre reinterpreta os símbolos a seu favor e subverte o sentido pretendido por Dario: o chicote representaria as armas pelas quais ele combateria e submeteria os persas, a bola seria uma representação do mundo que ele dominaria, e o cofre de outro indicaria os tributos que Dario, derrotado e subjugado, teria de lhe pagar. Embora possam se encontrar relatos análogos precedentes em Heródoto (Histórias, 4.131-132) e em Ferécides de Siros (FGrHist 3 F 174, a partir de Clemente de Alexandria, Estrômata, 5.8.44), 
alguns traços característicos no $\mathrm{R} A$, segundo Konstantakos, permitiriam uma relação mais apropriada com o padrão arcaico do conto relativo à metamorfose ou transformação mágica, quais sejam: a leitura de Alexandre transforma o sentido inicial dado por Dario (concernente à infância e à fraqueza) em símbolos de força, poder e conquista; há uma gradação crescente entre os sentidos dados por Alexandre. Dessa forma, Alexandre e Dario estão engajados numa espécie de concurso em que se utilizam da linguagem para transformar objetos em noções competitivas; ambos manipulam o discurso em função de um conflito político, em que dois estados e povos se medem como inimigos, buscando um domínio do outro. Por sua vez, Alexandre, retratado como um consumado trickster, excelente descobridor de enigmas e adivinhas, se revela mais sagaz nessa competição discursiva, e sua vitória no discurso já prenuncia sua vitória nas batalhas efetivas contra Dario.

Quanto ao segundo ponto desse trabalho, a relação entre Alexandre e outros deuses e heróis, mormente Héracles, Dioniso, Amon e Aquiles, tem sido posta em relevo por diversos especialistas, não apenas no $\mathrm{R} A$, mas nas fontes coevas e posteriores às conquistas e morte do rei macedônio. Ory Amitay (2002) faz um levantamento em fontes historiográficas e outras mais genéricas sobre o emprego e a analogia com Héracles (e, em menor medida, com Dioniso) para a interpretação e constituição da imagem e das ações de Alexandre. Estando estreitamente vinculado à origem da casa real da Macedônia, ${ }^{3}$ a figura e o mito de Héracles se convertem em moeda de troca política e cultural para os mais diversos fins; Alexandre, por exemplo, apela justamente para as raízes comuns dos tessálios relativamente a Héracles para os convencer a se submeterem a seu domínio, ainda que tal fato tenha sucesso em vista também das promessas e ameaças feitas por ele. ${ }^{4}$ Amitay aponta vários feitos e façanhas de Alexandre em que se busca uma afiliação proposital com determinadas divindades ou heróis: ao atravessar a margem da fronteira norte do Rio Istros, atualmente Danúbio, Alexandre realiza sacrifícios a Zeus Salvador (Sotér), Héracles e ao próprio rio. É salientado nessa sua primeira empresa como rei, dominando e submetendo as tribos do norte, seu póthos, desejo ardente de ir além, além de seus predecessores, para além das fronteiras estabelecidas. Isso é um traço tradicionalmente retomado pelos comentaristas antigos e modernos e que divisamos em vários momentos do $\mathrm{R} A$. Na travessia do Helesponto, em ambas as margens, Alexandre erige altares a Zeus Apobatérios (que protege o desembarque), Atena e Héracles. Essa é uma cena importantíssima no $\mathrm{R} A$, que mencionaremos ulteriormente. São, dessa forma, retomadas e assimiladas para a constituição da imagem propagandeada de Alexandre várias qualidades reportadas a Héracles, sempre com um verniz de pan-helenismo: seu poder pacificador, seu caráter civilizatório, levando ordem e cultura aos territórios selvagens, seu caráter emblemático de marcar as fronteiras do mundo civilizado, seu pónos (seu trabalho árduo para alcançar com sucesso seus objetivos), sua habilidade de guerreiro e de conquistador de cidades, sua ação de fundar cidades e construir colônias gregas em terras distantes (Amitay, 2002, p. 1-84).

\footnotetext{
${ }^{3}$ Cf. Teopompo de Quios, FGrH 115 F393; Heródoto, Histórias, 5.22, 8.13; Amitay (2002, p. 1).

${ }^{4}$ Cf. Diodoro, 4.3.23, 17.4.1.
} 
Quanto à utilização da comparação entre Alexandre e Aquiles nas diversas fontes, Judith Maitland indica duas maneiras de reapropriação: 1) uma remessa puramente romanceada, por assim dizer, literária; 2) uma abordagem temática negativa e hostil a Alexandre, constante de parte da dita "vulgata", utilizada por Curtius e Diodoro. Para ela, seria Hegésias de Magnésia a provável fonte, especialmente para Curtius, desse segundo modo de comparação entre Alexandre e Aquiles, pondo em evidência características negativas: em primeiro lugar, a ira incontrolável, como, por exemplo, no caso de Clito, morto por Alexandre num ataque de fúria; em segundo lugar, a tendência ao isolamento, em que ele se retira à tenda ou aos aposentos quando não atendidos seus desejos e comandos: quando da passagem pelo rio Hífasis na Índia, a tropa se recusa a obedecer e ele fica recolhido em sua tenda (Maitland, 2015, p. 1-20). Por seu turno, para Heckel, os relatos que vinculam Alexandre a Aquiles seriam fabricações literárias tardias e não fariam parte da agenda política coeva de Alexandre concernente à divulgação de sua imagem como herói. Por outro lado, o uso de Héracles, bem como de outros deuses e heróis determinados, estava no centro da propaganda oficial do macedônio, a exemplo da cunhagem de moedas com a efígie de Héracles: a pele de leão e a clava assinalariam os traços do herói mítico, enquanto o rosto barbeado, segundo Heckel, remeteria não a Héracles jovem, mas ao próprio Alexandre, havendo uma fusão das imagens de ambos. O programa de preceitos religiosos por Alexandre, reportados pelas principais fontes, se centraria, segundo Heckel, em torno das figuras de Zeus, Héracles e Atena, o que é um dado importantíssimo no cotejo com o $\mathrm{R} A$, em que a valorização de deuses e heróis é diferenciada, além de variável em função da preferência das várias recensões da obra (Heckel, 2015, p. 21-34).

Cares de Mitilene, Erastóstenes e Megástenes são as fontes que reportam a formação e propagação do mito de Dioniso na Índia. Diodoro, Ptolomeu e Clitarco se utilizam dessas fontes para fomentar as relações e traços similares entre Alexandre e o deus, buscando realçar seu papel divino. É salientado por eles o papel de Dioniso como conquistador e civilizador, o que o faz, inclusive para Arriano, um paradigma inspirador para o macedônio. Segundo Ilias Koulakiotis, embora se possa encontrar tais comparações em Arriano, Curtius, Diodoro e Justino, mormente durante as empresas de Alexandre na Índia, é na obra biográfica de Plutarco que a relação entre Alexandre e Dioniso é explorada de modo mais explícito e consistente. As temáticas para a analogia com os aspectos desse deus estariam centradas em temas relativos a jogos e bebidas, o que acarretaria, segundo Koulakiotis, ${ }^{5}$ uma depauperação de Alexandre e uma perda gradual de carisma e poder. Esse estudioso chama a atenção para o êthos negativo das ações perpetradas por Alexandre quando relacionadas à esfera ou a aspectos de Dioniso: a devastação de Tebas, o assassinato de Clito e a queima do palácio de Persépolis, este ocorrido em 330 a.C. Na expedição para a Índia, em Carmânia, Alexandre realiza um kómos, um cortejo de caráter báquico, justamente dedicado ao deus

\footnotetext{
${ }^{5}$ Além disso, haveria uma abordagem em Plutarco com um enquadramento duplo: paidiá e rêma $(\dot{\rho} \tilde{\mu} \mu \alpha)$. O segundo termo diz respeito à ambientação oral, frase, palavra ou comentário em geral; o primeiro concerne, além das brincadeiras, a qualquer atividade teatral ou relativa a jogos (Koulakiotis, 2017, p. 230).
} 
considerado conquistador da Índia, tendo como propósito também sua própria deificação. Não obstante, a partir de então se inicia a reversão do percurso de Alexandre que tem como final, no relato plutarqueano, a bebida excessiva de vinho que o leva à morte. Desse modo, segundo Ilias Koulakiotis, a relação buscada entre Alexandre e Dioniso, mormente no texto plutarqueano, visaria essa sinalização de perda de carisma e poder por parte de Alexandre, Dioniso assumindo um papel punitivo e de reversão da fortuna (Koulakiotis, 2017, p. 226-49).

Em vista de todas essas comparações entre Alexandre e deuses e heróis, bem como de seus aspectos e funções variados, cabe, a princípio, verificar nas recensões ${ }^{6}$ do $R A$ as nuances e reformulações dessas relações a partir da dinâmica do texto (em vista do escopo desse trabalho, vou me restringir ao livro 1). É, ademais, igualmente relevante para os propósitos deste trabalho situar e avaliar as cenas em que algum dito ou comentário de caráter filosófico é expresso por Alexandre ou algum de seus interlocutores. Com esse duplo intuito, elenco algumas passagens do texto mais relevantes para esses dois tipos de referência.

No livro 1, Olímpia, esposa de Filipe, faz uma consulta a Nectanebo (na narrativa, este último faraó do Egito teria se refugiado na Macedônia e atuaria na região como adivinho e mago): ela temia ser repelida pelo rei, uma vez que não tinha conseguido gerar um filho. Nectanebo consulta uma tábua astrológica e declara que isso poderia ser resolvido caso ela concebesse um filho com o deus Amon do Egito. Quando Nectanebo assevera que ela própria sonharia com o deus que, por sua vez, se uniria a ela, Olímpia faz a seguinte réplica: "Se eu vir isso, não como um mago ou profeta, mas como um deus te farei reverência!" ( $\mathrm{R} A, 1,4,10$; recensão $\alpha$ ). Esse é um passo importantíssimo em função de pôr em evidência os seguintes aspectos: a) o caráter jocoso da narrativa que brinca com o duplo sentido das falas das personagens; b) a remessa consciente à esfera da recepção, pois o leitor está consciente do engodo tramado por Nectanebo; c) a alternância ou concomitância entre homem e deus (aqui concernente à figura de Nectanebo, o qual se disfarça e representa o papel de vários deuses e heróis), que será destinada ulteriormente para a figura de Alexandre; d) além de enfocar a temática da reverência divina a uma figura humana sob o prisma do gênero sériocômico, o passo se conecta a outros que abarcam referências literárias diversas, o que pode dar indicações metaliterárias e aclarar algum tipo de intencionalidade da obra. Dessa forma, podemos corroborar alguns dados da análise de Grammatiki Karla, em que a unidade da obra se desvela mais em função desses elementos e aspectos que são retomados e reformulados para personagens e circunstâncias diferentes. Além disso, há o estabelecimento de um jogo entre a esfera da narrativa e da recepção: o encontro e união entre Olímpia e Nectanebo adquire um caráter preparatório, em que vários elementos são postos e lançados para o desfrute e consideração do leitor.

Em seguida a esse primeiro contato, a rainha sonha com o deus Amon e reporta a Nectanebo, o qual faz uma série de orientações e procedimentos quanto ao modo do conúbio sexual entre ela e o deus:

\footnotetext{
${ }^{6}$ Aqui vou me restringir à recensão $\alpha$, a partir da edição crítica de Richard Stoneman (2007).
} 
Penso então em tomar um quartinho perto de sua cama, a fim de que, vindo o deus, eu possa te auxiliar com ensalmos para você não ficar tomada pelo pavor. Pois este deus, vindo até ti, assumirá primeiro a forma de uma serpente que serpenteia na terra produzindo um silvo, depois se transformará em Amon com chifres, depois no portentoso Héracles, depois em Dioniso porta-tirso, depois, ao se reunir contigo, assumirá uma forma humana tomando as minhas feições $(R A, 1,6$, 2-3; recensão $\alpha$, tradução nossa).

Aparecem aqui os três deuses e heróis a que, inicialmente, Alexandre é relacionado: Amon, Héracles e Dioniso. Eles auguram seu nascimento e corroboram sua filiação divina. Não obstante, a cena forjada por Nectanebo ambienta tais metamorfoses divinas numa forma de engano, em que as aparições dos deuses se convertem em disfarces, em figurinos de um ator, canastrão, que os emprega em proveito de seu interesse pessoal, no caso, seu desejo concupiscente (erotikès epithymías) de ter relações sexuais com a rainha. Tanto o engano encetado pelo egípcio, quanto o deixar-se enganar da personagem de Olímpia resvalam para a indicação do caráter fictício da trama, sem deixar de fazer referência ao percurso biográfico e, em certa medida, histórico divisado no relato. Amon é retratado com chifres, o que parece prefigurar as imagens oficiais da figura de Alexandre; além do mais, enfatiza sua região de procedência, Egito, e, em função de seu sincretismo com Zeus, sublinha a soberania como a qualidade, por excelência, de Alexandre. Héracles, por sua vez, é descrito como álkimon, o que retoma o lugar-comum relativo à força, violência e demais qualificativos guerreiros. ${ }^{7}$ Dioniso, por seu turno, recebe o epíteto de "portador do tirso", o que pode ser apenas uma distinção iconográfica ou apontar para procedimentos rituais; mais adiante $(R A, 1,7,2)$, ele é chamado de panthéou, todo-divino, o que parece chamar atenção para a temática da deificação, também importante para a imagem veiculada de Alexandre na narrativa.

De uma forma ou de outra, tais referências a deuses e heróis servem para uma dupla marcação: a) pontuam um fato biográfico importante, no caso, a concepção e, em seguida, o nascimento de Alexandre; b) pontuam a própria narrativa, em que se cria um sistema peculiar de sinalização diegética. A tal procedimento se associa outro igualmente importante: o relato de sinais, de sonhos, de presságios, seguido pela decifração ou explicação dos mesmos. Por exemplo, no sonho que Nectanebo, através de suas artes mágicas, insufla em Filipe, com o intuito de que o rei não repelisse Olímpia por traição, uma vez que teria sido um deus que a tinha engravidado. Eis o passo em $\alpha$ :

Viu de fato um formoso deus, grisalho, com chifres ao modo de Amon, estando deitado junto com Olímpia e, depois de se levantar da cama, dizendo a ela: "Tem seu ventre um filho de minha parte,

\footnotetext{
${ }^{7}$ Embora não haja aqui um tratamento mais sistemático desse qualificativo, esse termo é utilizado por Platão no célebre passo da República (614b): ao iniciar o relato do mito de Er, o personagem de Sócrates adverte que não narrará um mito relativo a Alcínoo, mas um mito “álkimon”, vigoroso. Dessa forma, não se pode descartar uma referência metaliterária.
} 
que vem a ser teu vingador e de Filipe". Ficou com a impressão de que ele costurou na natureza dela um papiro do Nilo e colocou com seu selo de ouro uma incisão em pedra que continha uma cabeça de leão, a potência do sol e uma pequena lança. Pareceu que um falcão, com suas asas, o acordava. ( $R A, 1,8,2-3$; recensão $\alpha$, tradução nossa)

Aqui a referência indireta parece ser Héracles, em função da cabeça de leão, o que parece ser corroborada pela decifração pelo adivinho: o filho conquistará, pela força, as terras que se estendem do nascer ao pôr do sol. A temática das fronteiras do mundo habitado está também insinuada, a princípio, associada a Héracles. Embora não apareça nesse passo o termo 'kosmokrátor', é essa acepção de 'dominador do mundo' que subjaz ao sentido proposto do sonho. A passagem como um todo é emblemática: um papiro do Nilo é costurado por cima do órgão sexual de Olímpia; talvez o jogo encenado pela narrativa indique a procedência do pretenso pai de Alexandre como a origem da própria obra ou do anônimo escritor da obra. ${ }^{8} \mathrm{Na}$ sequência da narrativa acontece um outro portento: enquanto Filipe estava sentado num lugar sossegado, em meio a livros próprios de letrados (philológois), uma ave doméstica põe em seu colo um ovo, que se racha ao cair no solo; dele sai uma pequena serpente que, depois de dar a volta ao ovo, morre antes de conseguir entrar novamente. Segue-se o mesmo procedimento: alguém encarregado de decifrar emite uma explicação pertinente; no caso, significaria que ele teria um filho que reinaria e circundaria o mundo inteiro, submetendo a todos; a serpente é um símbolo da realeza, e o ovo, do mundo. Não obstante, o filho morreria jovem, no momento em que buscasse voltar para a pátria. Em ambos os sinais e subsequentes explicações, são retomados elementos aventados anteriormente por ocasião da concepção e nascimento de Alexandre.

$\mathrm{Na}$ sequência, na cena que é a mais satírica e cômica do $\mathrm{R} A$ se faz, ao final dela, nova menção a Dioniso. Olímpia, sentando-se numa cadeira própria para o parto, é impedida de parir repetida vezes por Nectanebo, em vista das circunstâncias adversas e da posição não adequada dos astros, até chegar o momento considerado propício por ele:

Com efeito, Zeus, aficcionado em virgens, que deu à luz a Dioniso, criado em sua coxa, deus do 'evoé', estando claro no meio do céu e assumindo a forma de Amon, tendo passado por Aquário e Peixes, reestabelece/reinstaura um homem egípcio como conquistador do mundo (kosmokrátora). Eis a hora: gera! $(\mathrm{R} A, 1,12,8$; recensão $\alpha$, tradução nossa)

Como esclarece Grammatiki Karla, o termo kosmokrátor é de proveniência oriental, utilizado especialmente como qualificativo dos faraós do Egito. ${ }^{9}$ Ele é empregado várias

\footnotetext{
${ }^{8}$ Segundo a opinião da maior parte dos especialistas, o $\mathrm{R} A$, nessa recensão $\alpha$, teria um autor procedente de alguma região helenizada do Egito, provavelmente um alexandrino (cf. Nawotka, 2017, p. 3-10). ${ }^{9}$ Segundo esclarece Krzysztof Nawotka, uma expressão egípcia correlata, ' $n d r \underline{d} r$, era utilizada desde o Médio Império Egípcio para epíteto dos principais deuses egípcios, como Osíris, Amon e Rá. O termo kosmokrátor, por seu turno, em fontes gregas foi empregado poucas vezes para mortais: além
} 
vezes para Alexandre (como visto anteriormente, no sinal antes de seu nascimento: 1, 11, 1-4 (aqui não aparece o termo em si, mas o sentido de que dominará o mundo), durante o nascimento: 1, 12, 8, durante seus anos de formação: 1, 16, 5; 1, 17, 5; 1, 24, 9), para Sesôncosis, faraó do Egito ( 1 , 33, 6; 1, 37, 23-5; 3, 24, 2; 3, 34, 4, 18-20) e uma vez para Filipe $(1,24,10)$. Na passagem em questão está vinculado a Zeus, Dioniso e Amon e é, da forma como analisada por Karla, um motivo recorrente que perpassa a narrativa. Entretanto, os epítetos aí escolhidos para individualizar Dioniso parecem modalizar sua apresentação na narrativa, chamando atenção para os elementos rituais (eúios, évio, concernente ao grito ritual 'evoé) e para particularidades míticas do seu próprio nascimento (gerado na coxa de Zeus). Não se pode deslindar disso o aspecto duplo e paradoxal de Dioniso: um herói que é deificado, um deus que morre.

O outro procedimento discursivo amplamente utilizado na narrativa, que pode aparecer entrelaçado com os anteriores, é a constituição de cenas apotegmáticas, em que há um dito ou fecho final apresentando um preceito ético, uma questão filosófica ou tipo de moral da história. Esse, na verdade, é o modo mais característico da narrativa do $\mathrm{R} A$ e o que empresta uma unidade especial à obra, haja vista pontuar cenas importantes e servir como marcação de unidades narrativas. No primeiro livro, a cena mais impactante que exemplifica tal procedimento é a da morte de Nectanebo. Ao se apresentar novamente à rainha, Nectanebo faz uso de sua placa astrológica, fato que insufla Alexandre a indagar sobre os astros; em função disso, aquele convida o filho para observar os astros à noitinha e lhe ensinar sobre astrologia. Na passagem, há um comentário do narrador ironizando o personagem: como alguém que realizou tamanhas empresas como profeta através da magia, não de pouca estatura na astrologia, predizendo eventos a se realizar no futuro, não conseguiu prever a desgraça a si disposta ao tomar as mãos de Alexandre? A morte de Nectanebo assume ares tragicômicos, em que ambos os personagens enunciam princípios éticos:

Nectanebo, com efeito, o conduz para fora da cidade e, alçando o olhar para o céu, mostra-lhe as estrelas, ensinando-lhe seus próprios artifícios. Alexandre, porém, levantando-lhe nos ombros, o arroja num lugar íngreme e de difícil acesso. Tendo aí despencado e batido funestamente contra a cabeça, diz: "Meu filho, Alexandre, por que você achou de fazer isso?" E o outro respondeu: "Censura a ti mesmo, astrólogo!" E ele diz: "Por quê?" E aquele respondeu: "Porque, não conhecendo as coisas sobre a terra, você busca investigar as do céu!" E ele disse: "Findo minha vida, Alexandre: de forma tremendamente funesta tomo par da situação. Pois bem, não é possível a nenhum mortal vencer o destino que lhe está posto. De

de usado para Alexandre, Sesôncosis e Felipe II no $\mathrm{R} A$, aparece referido ao rei Arquelau (Miguel Pselos, Teológica, 96), a Caracala, Gordiano III e aos tetrarcas em inscrições (IGR I.1063; IG XIX.926; IG III.387; SEG 25.746). Na literatura cristã é usado bastante em referência a Satã. Na literatura não cristã mais tardia, aparece em obras astronômicas, comentários a Aristóteles e a Platão, hinos órficos e papiros mágicos, comumente aplicados a planetas, ao sol e à lua (cf. Nawotka, 2017, p. 67-8). 
fato, quando consultei meu próprio destino, achei o que me estava reservado: ser destruído por meu próprio filho; não consegui escapar de tal destino: fui destruído por ti". E Alexandre falou: "Eu então calho de ser seu filho." E ele disse: "Sim, filho!”. (RA, 1, 14, 4-7; recensão $\alpha$, tradução nossa) ${ }^{10}$

O dito de Alexandre retoma um lugar comum, cujos antecedentes mais conhecidos são reportados à figura de um astrólogo ou a Tales de Mileto. ${ }^{11}$ Constituída como chréia ou apotegma, a cena apresenta, de início, aspectos de uma moral pragmática: não buscar conhecer coisas da ordem do inatingível, não descurar da realidade efetiva. Nectanebo, por seu turno, dirige a interpretação num outro sentido: sendo mortal, não se pode fugir daquilo que lhe está destinado. Além disso, são enfatizadas pelo narrador as qualidades daquele como profeta, mago e adivinho; disso depreende-se que alguém não pode, em vista da mudança das circunstâncias, estar seguro de sua própria posição e, no caso, de sua própria sobrevivência. A intensidade satírica da cena também advém do fato de a queda de Nectanebo, sua perda de status e da própria vida, provir de uma queda efetiva na narrativa, fazendo uso de lugar comum bastante conhecido. Tal cena, ademais, exemplifica o jogo sério-cômico que é orquestrado ao longo da narrativa e se conecta, em rede, a outras passagens em que há a enunciação de algum princípio ético-filosófico. A temática principal desse tipo de cena apotegmática gira em torno de alguns aspectos: 1) a explicitação dos limites humanos, em que se reportam modos de atentar contra esses limites; 2) a busca da deificação e da imortalidade; 3) o contraponto sinalizado pela morte que atinge os personagens principais; 4) a enunciação de comentários arrogantes e de atitudes soberbas, seguida pela derrocada daqueles que se vangloriavam; 5) a explicitação de um modo de vida que incorpora as circunstâncias adversas dentro de um enquadramento que as reordena como parte de um destino; 6) as mudanças da fortuna são um momento de aprendizagem: posições, cargos, governos são da ordem do transitório.

Em função de verificar o alcance desses dois dispositivos narrativos (a) comparações com deuses ou heróis e (b) enunciação de princípios éticos ou de algum tipo de moral na obra, assim como de um terceiro dispositivo (c) que lhes está relacionado, concernente a sinais, sonhos, presságios e suas decifrações, montei um quadro com as passagens mais representativas:

\footnotetext{
${ }^{10} \mathrm{Em}$ vista de uma marcação estilística, optei por mesclar os registros de terceira e segunda pessoas em algumas frases, no intuito de criar um ar de maior coloquialidade ou, ao empregar apenas a segunda pessoa, de maior formalidade para certos personagens em ocasiões específicas.

${ }^{11}$ Ver toda a exposição e comentário sobre este específico lugar-comum no texto "Alexandre: lugares comuns, personagem incomum” de Jacyntho Lins Brandão presente neste dossiê; cf. Diógenes Laércio, I, 34; Platão, Teeteto 174a.
} 


\section{QUADRO DE PASSAGENS DO LIVRO 1, RECENSÃO A: ${ }^{12}$}

1) (b) Tendo assim falado o comandante do exército, Nectanebo, dando um sorriso, falou: "Você guarda bem e em vigília os postos de segurança que te foram confiados, mas se expressa de forma covarde e não apropriadamente como um soldado, pois a força não se manifesta na massa, mas no arrojo do ânimo; e, com efeito, um único discurso compele inúmeros, um braço valoroso envolvendo a multidão." Assim falando, despachou o outro. $(R A, 1,2,3$; recensão $\alpha)$

2) (a) Penso então em tomar um quartinho perto de tua cama, a fim de que, vindo o deus, eu possa te auxiliar com ensalmos para não ficares tomada pelo pavor. Pois este deus, vindo até ti, assumirá primeiro a forma de uma serpente que serpenteia na terra produzindo um silvo, depois se transformará em Amon com chifres, depois no portentoso Héracles, depois em Dioniso porta-tirso, depois, ao se reunir contigo, assumirá uma forma humana tomando as minhas feições. ( $R A, 1,6,2-3$; recensão $\alpha$ )

3) (a) Viu de fato um formoso deus, grisalho, com chifres ao modo de Amon, estando deitado junto com Olímpia e, depois de se levantar da cama, dizendo a ela: "Tem seu ventre um filho de minha parte, que vem a ser teu vingador e de Filipe". Ficou com a impressão de que ele costurou na natureza dela um papiro do Nilo e colocou com seu selo de ouro uma incisão em pedra que continha uma cabeça de leão, a potência do sol e uma pequena lança. Pareceu que um falcão, com suas asas, o acordava. ( $R A$, $1,8,2-3$; recensão $\alpha)$

4) (a) Com efeito, Zeus, aficionado em virgens, que deu à luz Dioniso, criado em sua coxa, deus do 'evoé', claro no meio do céu, assumindo a forma de Amon, tendo passado por Aquário e Peixes, reestabelece/reinstaura um homem egípcio como conquistador do mundo (kosmokrátora). Eis a hora: gera! $(\mathrm{R} A, 1,12,8$; recensão $\alpha)$

5) (a) [...] desde então o menino, seu filho, evoluía (no treinamento cuidadoso) e na idade; não tinha a estampa semelhante nem a Filipe nem a Olímpia; apresentava um tipo característico, com aspecto de cabeleira de leão, sendo os olhos de cor diferente, pois tinha um claro e outro escuro; e os dentes pontiagudos como cavilhas, e o arrojo de um leão selvagem. Tinha a natureza que evidenciava que tipo de pessoa resultará em ser. $(R A, 1,13,3$; recensão $\alpha)$

6) (b-c) E então certa vez os chefes da Capadócia levam a Filipe como presente um potro de sua tropa de cavalos, de tamanho enorme, guarnecido por inúmeras correntes que o atavam, dizendo tratar-se de animal antropófago. Ao considerar o quanto calhava de ser belo, disse: “Cumpre-se nele o dito proverbial: 'Do lado do bom engendra-se junto o mal”'. (RA, 1, 13, 6-7; recensão $\alpha)$

7) (b-c) Nectanebo, com efeito, o conduz para fora da cidade e, alçando o olhar para o céu, mostra-lhe as estrelas, ensinando-lhe seus próprios artifícios. Alexandre, porém,

\footnotetext{
${ }^{12}$ Todas as traduções dos trechos da recensão $\alpha$ do Romance de Alexandre são de minha autoria.
} 
levantando-lhe nos ombros, o arroja num lugar íngreme e de difícil acesso. Tendo aí despencado e batido funestamente contra a cabeça, diz: "Meu filho, Alexandre, por que você achou de fazer isso?” E o outro respondeu: “Censura a ti mesmo, astrólogo!” E ele diz: "Por quê?” E aquele respondeu: "Porque, não conhecendo o que há sobre a terra, você busca investigar as do céu!" E ele disse: "Findo minha vida, Alexandre: de forma tremendamente funesta tomo par da situação. Pois bem, não é possível a nenhum mortal vencer o destino que lhe está posto. De fato, quando consultei meu próprio destino, achei o que me estava reservado: ser destruído por meu próprio filho; não consegui escapar de tal destino: fui destruído por ti". E Alexandre falou: "Eu então calho de ser seu filho." E ele disse: "Sim, filho!” E Alexandre falou: "Eu então calho de ser seu filho.” E ele disse: “Sim, filho!”. E o outro disse: “Como isso ocorreu?” E Nectanebo narrou para ele sua fuga do Egito, sua inserção junto a Olímpia, o modo como entrou junto a ela como deus Amon e transou com ela. E, tais narrações enunciando, expirou. $(\mathrm{R} A, 1,14,4-7$; recensão $\alpha)$

8) (c) Felipe, retornando à sua morada real, mandou fazer uma consulta ao oráculo de Delfos no intuito de saber quem iria reinar depois dele e subjugar a todos pela lança. E disse o oráculo: "Aquele que, montando sobre o cavalo Bucéfalo, conduzi-lo pelo meio de Pela”. E o cavalo era chamado Bucéfalo, uma vez que assim expressou a marca de fogo na coxa em forma de cabeça de boi. Ao ouvir o oráculo, Filipe esperava contemplar um novo Héracles. ( $R A, 1,15,1-2$; recensão $\alpha)$

9) (b) E ele também perguntou a Alexandre: "E, você, filho, quando receber o legado real da parte de teu pai, como será útil a mim, a seu Mestre?” E o outro respondeu: "Sobre coisas futuras você indaga, sem ter garantia do dia de amanhã? Eu então farei a oferta, se me parecer bem, quando sobrevierem o tempo e a época oportunos para manter a promessa." E disse Aristóteles: "Bem-vindo [Khaírois], poder-no-mundo/

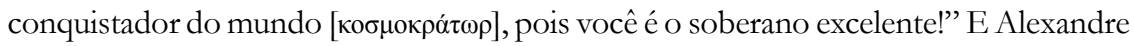

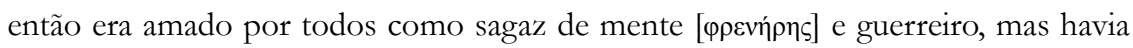
em Filipe um sentimento ambivalente, pois ficava bem [ékhaire] vendo o seu caráter belicoso, mas ficava triste por não ser semelhante a ele, vendo-o possuidor de um tipo físico próprio e peculiar. $(\mathrm{R} A, 1,16,3-5 \mathrm{a}$; recensão $\alpha)$

10) (c) Mas Alexandre, ao contemplar a aparência nova do cavalo e os cadáveres dilacerados, teve pena, como homem, e, afastando os guardas, abriu a cela [...] estando confiado nesta disposição; agarrou a crina do cavalo, o qual se submeteu à vontade dele (... ele teria nascido indomável/ dali podia sair sem rédeas). E alguém, correndo, anuncia a Filipe o ocorrido. E ele, tendo relembrado o oráculo, foi ao encontro do filho e o cumprimentou dizendo: “Alexandre, poder-no-mundo, para mim bem-vindo!". (RA, 1, 17, 4-5; recensão $\alpha$ )

11) (b) E, aproximando-se de Alexandre, o cumprimentou, ao mesmo tempo querendo saber em que participaria: "Bem-vindo, rapazote!” E o outro respondeu: "Seja bemvindo você, quem quer que possa ser!" "A quem acaso se dirige, a mim? Eu sou 
Nicolau de nome, rei dos acarnenses." E ele redarguiu: "Não se vanglorie dessa forma, rei Nicolau, como se tivesse suficiente garantia acerca do dia de amanhã. A fortuna [ ̛́xๆ] não está firme sobre nenhum lado, e o prato da balança muda sua inclinação e degola os arrogantes". (RA, 1, 18, 6-7; recensão $\alpha)$

12) (b) E, em quarto, estava Alexandre na condução do seu carro; atrás vinha Nicolau, não assim disposto para vencer, mas para aniquilar Alexandre, pois o pai de Nicolau tinha sido aniquilado por Filipe na guerra. Cônscio então disso, o sagaz Alexandre, estando para cair os condutores dos primeiros carros, deixa passar Nicolau. Nicolau, crendo ter vencido Alexandre, passa na dianteira tendo esperanças de ser coroado como vencedor. Mas depois de duas, três voltas, o cavalo direito de Nicolau tropeça e derruba todo o carro, junto com o condutor. E Alexandre, sobrevindo ao fragor de seus cavalos, aniquila na mesma hora Nicolau. E ele sobe junto ao templo de Zeus, coroado com ramo de oliveira. O oficial do templo lhe diz: "Alexandre, como você venceu Nicolau, assim vencerá também inúmeros inimigos”. ( $R A$, 1, 19, 4-6; recensão $\alpha$ )

13) (b) E Filipe se levanta de espada em punho contra seu próprio filho Alexandre, com a intenção de aniquilá-lo. No entanto, ao escorregar e cair junto aos assentos, disse Alexandre: "Aquele que se arvora em se apoderar da Ásia e assolar a Europa não conseguiu alternar o passo (dar um passo em seguida de outro)". (RA, 1, 21, 3; recensão $\alpha$ )

14) (b) Tendo despachado seu inimigo a um fim mais rápido que o seu, Filipe, reanimado pela presença de Alexandre e pela vingança a galope, disse: "Meu filho Alexandre, te está destinado ser conquistador do mundo; lembra-te de teu pai Filipe e não te recuses a me chamar de pai. Cumpre-se agora o meu destino." Tais palavras dizendo, expirou o espírito. Pranteando-o, disse Alexandre: "Meu pai Filipe, rei dos reis, ninguém, durante sua vida, se alegrou de te menosprezar. E agora, superior aos guarda-costas inaptos no tiro, teu braço não falhou contra Pausânias. Como pode, depois de ferido, ser aniquilado um conquistador do mundo? O ciclope Pausânias te enviou para junto dos deuses antes do estabelecido pelas Moiras, pelo que a justiça lhe retribuiu com a recompensa que lhe era própria!’. ( $\mathrm{R} A, 1,24,9-10$; recensão $\alpha)$

15) (a, b, c) Alexandre indagou de quem eram os obeliscos. E eles responderam: "Do rei

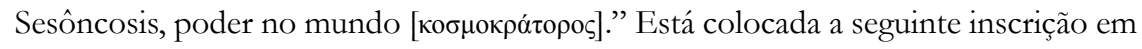

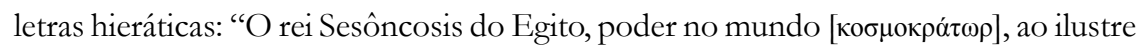
deus do mundo Serápis dedicou". [...] E Alexandre (em sonho) disse: "Senhor, ainda isso me mostra: quando e como devo me mudar dessa vida?” E o deus respondeu: "Sem dor, belo e valioso ao que veio a ser mortal é não saber de antemão quando é o limite do fim da vida. Com efeito, mesmo sendo mortais, intuem em seu íntimo que imortal é a vida em sua variedade, quando ainda possuem ignorâncias das desventuras. Isso mesmo considere também você ser aquilo que há de mais belo: não conhecer de antemão o futuro que lhe cabe, querido!”. (RA, 1, 33, 6-10; recensão $\alpha)$ 
16) (b-c) E Alexandre vê uma estátua de pedra negra e uma inscrição na base: "O rei que fugiu de novo virá ao Egito, não estando velho, mas remoçado, e submeterá para nós os nossos inimigos persas". E indagou de quem era a estátua. Eles responderam: "Este é o que foi o nosso último rei, o qual, vindo os persas para guerrearem contra o Egito, viu, através de sua potência mágica, que os deuses dos egípcios calhavam de estar entre as forças de guerra dos inimigos e, cônscio da traição ocorrida da parte deles, fugiu. Depois de buscarmos por ele e inquirirmos aos deuses para onde tinha fugido o rei, a voz do abscôndito sacrário de Sínope assim falou: 'O rei que fugiu de novo virá ao Egito, não estando velho, mas remoçado, e submeterá para nós os nossos inimigos persas"”. Ao ouvir tais palavras, Alexandre salta por sobre a estátua e a abraça dizendo: "Este é meu pai e dele calho de ser filho. O oráculo não mentiu a você. Deveras me admira que vocês tenham sido conquistados por bárbaros, possuindo tais muralhas não construídas por mãos humanas, não passíveis de serem derrubadas por inimigos. [...] Mas isto veio a partir da providência e da justiça dos deuses, de tal modo que vocês, possuindo a terra fértil e rio fecundo, fossem submetidos por aqueles que não têm em seu poder tais coisas. ( $\mathrm{R} A, 1,34,3-8$; recensão $\alpha$ )

17) (a-c) Alexandre buscava saber de que modo se apoderaria dos habitantes de Tiro, pois julgava impensável uma derrota advinda por eles. Vê, em sonhos, um sátiro, servidor de Dioniso, dando-lhe um queijo, e ele segurando-o para calcar-lhe sob os pés. Ao se levantar, narrou isso a um intérprete de sonhos. E o outro falou: "Rei Alexandre, Tiro vai estar sujeita às suas mãos, pelo fato de o queijo ter sido esmagado sob seus pés." Assim então avaliou o sonho o intérprete de sonhos. ( $R A, 1,35,7-8$; recensão $\alpha$ )

18) (a, b, c) Chegou no território dos agrigentinos e, entrando no santuário de Apolo, pedia àquela que enuncia o oráculo de Febo para lhe fazer uma consulta. Quando ela disse que não poderia prestar consulta ao oráculo, ele, encolerizado, disse: "Se você não quer vaticinar, eu mesmo vou carregar comigo a trípode, tal qual Héracles carregou a trípode enunciadora do oráculo de Febo, que foi ofertada por Creso.” Mas veio-lhe a voz do abscôndito do templo: "Héracles, Alexandre, fez tal ação de deus para deus, mas tu, sendo mortal, não queiras aos deuses te contrapor, pois as tuas ações vão ser comentadas até chegarem aos deuses". Depois de assim emitida a voz, disse a profetiza oracular de Febo: "O próprio deus vaticinou para ti apelando (chamando-te) por um nome mais poderoso, pois clamou provinda dos espaços abscônditos; Héracles, Alexandre, isto é o que te indica: que tu deves ser mais poderoso do que todos nas ações e serás relembrado pelas eras". ( $R A, 1,45,1-4$; recensão $\alpha)$

19) (a-b) De Zeus e Sêmele, parido no fogo, Dioniso em Tebas $<$ foi gerado $>$, Héracles da parte de Zeus e Alcmena foi semente aí engendrada. Estes surgiram para prestar ajuda a todos os homens e como partidários da paz, guardiães da salvação. E eles

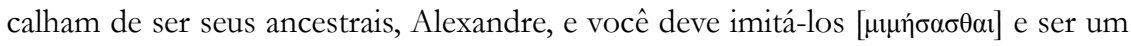
bem-feitor. Como você é um rebento da parte dos deuses, não despreze de Dioniso e Héracles a nutriz Tebas que está sendo destruída, nem devaste esta cidadela fundada pela vaca, pois vai ser uma vergonha posteriormente para os macedônios. Ignora você 
que é tebano e não de Pela. Toda a pátria dos tebanos lhe suplica por intermédio da minha voz, ela que traz em si os seus deuses ancestrais, Lineu membro da folia e da dança, Héracles de caráter justo nas ações e auxiliador dos homens. Tornando-se nesse momento mesmo imitador [ $\mu \mu \eta \tau$ rńs] dos seus antecessores, que tinham o bem e o valor no mais alto grau, converta estes atos de fúria em boa ação. Em vez de punir, tenha mais disposição para se apiedar. $(R A, 1,46 a, 4-7$; recensão $\alpha)$

20) (a) "Este é o recinto de Héracles, primeira morada de Anfitrião. Aqui dormiu Zeus, três noites conjugando numa única. Aí com raio Zeus então atinge sua desejada Sêmele. Daí, do meio do fogo, em si engravidou do taurino Dioniso Lineu. Aí Héracles enlouqueceu. Aí dentro, ensandecido, atingiu a mulher com um dardo. Este altar que vê é de Hera. [...] Aí Héracles, desgarrando-se da carne devorada pelo manto, foi posto em chamas pelas mãos de Filoctetes. [...]

Estás vendo, tomado pelo fogo, o recinto de Héracles, fundador da tua estirpe e de teu pai? Tu queres incendiar, ignorando, tais recintos a ti sagrados? Por que vilipendia os genitores que propiciaram tua geração, a estirpe de Héracles e do ínclito Baco?” Tantas súplicas tendo feito, Ismênias caiu aos pés do rei Alexandre. (RA, 1, 46a, 8; recensão $\alpha$ )

21) (a-c) E disse Clitômaco: "Eu tinha [uma cidade] antes de Alexandre se tornar rei, mas, depois que Alexandre se tornou rei, perdi minha pátria." E Alexandre, tomando ciência do que dizia e do que ia pedir, falou: "Que Tebas seja reconstruída em honra dos três deuses: Hermes, Héracles e Pólux.” E assim tornou realidade o oráculo de Apolo: Hermes, o Alcida [descendente de Alceu] e o pugilista Pólux, em concurso, vão te reconstruir, Tebas. $(R A, 1,47,7-8$; recensão $\alpha)$

Em vista dos limites deste trabalho, vou comentar apenas alguns passos e esboçar algumas conclusões provisórias. As figuras dos heróis funcionam na presente narrativa como balizas das ações e da conduta de Alexandre. Eles marcam um momento de inflexão na narrativa ou a exposição do caráter e do status do protagonista, evidenciando uma oscilação entre o divino e o humano. Por exemplo, quando a voz oracular de Febo busca conter Alexandre em seu arroubo de levar a trípode sagrada, ao mesmo tempo, ele toma consciência de que Héracles, como deus, o supera, mas também que suas futuras ações, equiparando-se às daquele, o tornarão famoso pelas eras. A presença de Dioniso, por seu turno, além de propiciar a resolução do embate (contra os tírios), parece trazer algo de funesto: a destruição impiedosa de Tiro. O mesmo se pode dizer de sua referência feita pelo auleta Ismênias. A princípio, Ismênias tenta apelar para a boa vontade de Alexandre, com o intuito de impedir a destruição completa de Tebas. De início, busca enfatizar as qualidades de Dioniso e Héracles como deuses salvadores, benfeitores da história da humanidade e que socorrem os homens na adversidade. Não obstante, na sequência, Ismênias, num discurso inoportuno, menciona justamente as desventuras e desgraças consoantes os mitos de ambos os heróis: Dioniso tem sua geração na coxa de Zeus em vista do fato de tudo ter sido carbonizado, inclusive sua mãe, ante a aparição de Zeus com o raio; Héracles, por seu turno, por portar o manto(khitón) envenenado e sofrendo dores incalculáveis, prefere morrer numa pira. O relato de eventos 
macabros em ambos os mitos (assim como em outros, como o de Édipo) surte o efeito contrário: Alexandre ordena a destruição completa de Tebas pelo fogo, poupando apenas a casa de Píndaro. O mito de Dioniso, contado por Ismênias, evidencia a relação buscada com o próprio nascimento de Alexandre, em que o epíteto aí usado, criado na coxa (cf. $\mathrm{R} A, 1,12,8$; recensão $\alpha$ ), assume um tom mais ameaçador, indicando um caráter punitivo e destrutivo. Embora no discurso de Ismênias Héracles também possua esse caráter negativo, na cena com o atleta Clitômaco, o herói, ao lado de dois outros deuses (Hermes e Pólux) seria responsável pela reconstrução de Tebas ordenada por Alexandre. Vinculado à ação do atleta, a figura de Héracles veicula as noções de esforço e labor que lhe eram paradigmáticas, além de evidenciar sua ação de deus civilizatório, a que se associam as ações e os discursos de Alexandre. A fundação de Alexandria apresenta também essa função no relato.

Quanto aos dois outros dispositivos aqui analisados -1) sinais, oráculos, seguidos de decifração ou explicação de seu sentido para as circunstâncias e 2) situação apotegmática seguida de princípio ético ou filosófico - aparecem eles às vezes interconectados na narrativa. As questões, por exemplo, feitas por Alexandre em sonho a Serápis têm como respostas princípios morais advogados pelo deus: não saber o próprio destino e o dia da morte, pois isto traria sofrimento e angústia aos homens. O encontro da estátua de Nectanebo fornece pistas e elementos importantes para pensar a unidade da obra: retoma-se o argumento do início da narrativa relativa à fuga de Nectanebo do Egito e sua ida à Macedônia; de modo inverso, Alexandre, vindo da Macedônia, chega ao Egito sendo coroado como rei e agraciado como senhor do mundo e conquistador dos povos inimigos. Alexandre, nessa seção, não se furta em emitir um princípio de natureza geral: a providência dos deuses explica questões e situações impensáveis, como a derrocada do Egito frente aos persas. É explorado, de maneiras variadas, ao longo do $\mathrm{R} A$, um jogo com as concepções de Providência e Fortuna, sobre o que não poderei me estender neste trabalho. De qualquer forma, tais concepções estão imbricadas e presentes nos três dispositivos aqui comentados e analisados. Em função da exposição de alguns modos da dinâmica narrativa, chega-se à conclusão de que, a despeito de ser uma obra aberta, mais permeável às diversas incorporações textuais, o $\mathrm{R} A$, nas formas que nos legaram as mais antigas recensões, apresenta um plano narrativo em que se desvelam dispositivos narrativos de caráter programático, os quais se encontram orquestrados e interconectados em rede na narrativa.

\section{REFERÊNCIAS}

AMITAY, Ory. Alexander Mythistoricus. Tese (Doutorado de Filosofia em História Antiga e Arqueologia Mediterrânea) - Divisão de Graduação na Universidade da Califórnia, Berkeley, 2002.

ASIRVATHAM, Sulochana. Alexander the philosopher in the Greco-Roman, Persian and Arabic traditions. In: STONEMAN, Richard; ERICKSON, Kyle; NETTON, Ian (ed.). The Alexander Romance in Persia and the East. Groningen: Barkhuis Publishing \& Groningen University Library, 2012, p. 311-26. 
BILLAULT, Alain. Le choix narratifs de Philostrate dans la Vie D'Apollonios de Tyane. In: DEMOEN, Kristoffel; PRAET, Danny (ed.). Theios Sophistes. Leiden: Brill, 2009, p. 3-19.

BOWIE, Ewen. Apollonius of Tyana: Tradition and reality. Aufstieg und Niedergang der römischen Welt, Teil II: Principat, v. 16, n. 2, p. 1652-99, 1978.

BOWIE, Ewen. Philostratus: writer of fiction. In: MORGAN, J. R.; STONEMAN, Richard. Greek fiction: The Greek novel in context. London: Routledge, 1994, p. 181-99.

BOWIE, Ewen. Quotation of earlier texts in TA E $\Sigma$ TYANEA AПO $\Lambda \Lambda \Omega N I O N$. In: DEMOEN, Kristoffel; PRAET, Danny (ed.). Theios sophistes. Leiden: Brill, 2009, p. 57-74.

BRANDÃO, Jacyntho Lins. A invenção do romance. Brasília: UnB, 2005.

BRANDÃO, Jacyntho Lins. A poética do hipocentauro: literatura, sociedade e discurso ficcional em Luciano de Samósata. Belo Horizonte: UFMG, 2001. v. 1.

BURRIDGE, Richard A. What are the Gospels? A comparison with Graeco-Roman biography. Michigan: William B. Eerdmans Publishing Company, Gran Rapids, 2004.

CALÍSTENES, Pseudo-. Vida e feitos de Alexandre da Macedônia. Tradução de Laura Cohen Rabelo. In: RABELO, Laura Cohen. Vida e feitos de Alexandre da Macedônia: tradução e comentário de um romance de Alexandre grego. Dissertação (Mestrado em Estudos Literários) - Programa de Pós-graduação em Estudos Literários da Faculdade de Letras, Universidade Federal de Minas Gerais, Belo Horizonte, 2017.

CIZEK, Alexander. Historical distortions and saga patterns in the Pseudo-Callisthenes Alexander Roman. Hermes, v. 106, n. 4, p. 593-607, 1978.

COX, Patricia. Biography in late Antiquity. A quest for the holy man. Berkeley: University of California Press, 1983, p. 17-44.

DEMOEN, Kristoffel; PRAET, Danny (ed.). Theios sophistes. Leiden: Brill, 2009.

DZIELSKA, Maria. Apollonius of Tyana in legend and history. Tr. Piotr Piénkowski. Roma: "L'Erma" di Bretschneider, 1986.

FILOSTRATO. Vidas de los sofistas. In: SANZ ROMANILLOS, Antonio; ORTIZ Y SANZ; José; M. RIAÑO, José (trad.). Biografos Griegos. Traduciones del griego y notas. Prólogo general por Juan Martin Ruiz Werner; preâmbulos parciales por F. de P. Samaranch y J. M. Riaño. Madrid: Aguilar, 1973.

FLINTERMAN, Jaap-Jan. Power, paideia \& pythagoreanism. Amsterdam: J. C. Gieben Publisher, 1995.

FISCH, M. H. Alexander and the stoics. The American Journal of Philology, v. 58, n. 2, p. 129-51, 1937. Disponível em: http://www.jstor.org/stable/290206. Acesso em: 7 set. 2017.

GALLO, I. La biografia greca. Profilo storico e breve antologia di testi. Rubbettino: Soveria Mannelli, 2005. 
GASSINO, Isabelle. Par-delà toutes les frontières: le pseudos dans les Histoires vrais de Lucien. In: MESTRE, Francesca; PILAR, Gómez (ed.). Lucian of Samosata, Greek writer and Roman citizen. Barcelona: Publications I Edicions de la Universitat de Barcelona, 2010, p. 87-98.

GRAHAM, Anderson. Philostratus on Apollonius of Tyana: The unpredictable on the unfathomable. In: SCHMELING, Gareth (ed.). The novel in the ancient world. Boston: Brill, 2003, p. 613-18.

GROSSO, Fulvio. La Vita di Apollonio di Tiana come fonte storica. ACME, v. 7, p. 333-532, 1954.

GYSELINCK, Wannes; DEMOEN, Kristoffel. Fiction and metafiction in Philostratus' Vita Apolonii. In: DEMOEN, Kristoffel; PRAET, Danny (ed.). Theios sophistes. Leiden: Brill, 2009, p. 95-128.

HÄGG, Tomas. The ideal Greek novel from a biographical perspective. In: KARLA, Grammatiki A. (ed.). Fiction on the fringe: novelistic writing in the post-classical age. Leiden: Bril, 2009, p. 33-48.

HANSEN, William (ed.). Ancient Greek popular literature. Bloomington: Indiana University Press, 1998.

HECKEL, Waldemar. Alexander, Achilles, and Heracles: Between Myth and History. In: WHEATLEY, Pat; BAYHAM, Elizabeth (ed.). East and West in the world empire of Alexander. Essays in honor of Brian Bosworth. Oxford: Oxford University Press, 2015, p. 21-34.

HOLZBERG, Niklas. The ancient novel. An introduction. London: Routledge, 1995.

IPIRANGA JÚNIOR, Pedro. Bíos e hibridização: biografia cristã e pagã. Classica, v. 21, n.1, p. 90-101, 2008. DOI: https://doi.org/10.14195/2176-6436_21-1_6

IPIRANGA JÚNIOR, Pedro. Cenas de amor e guerra na Ciropedia: concepções de gênero. In: IPIRANGA JÚNIOR, Pedro et al. (org.). Do amor e da guerra: um itinerário de narrativas. São Paulo: Annablume, 2014, p. 133-55.

IPIRANGA JÚNIOR, Pedro. O romance antigo: teorização e crítica. Eutomia, v. 1, p. 45-65, 2015.

IPIRANGA JÚNIOR, Pedro. Romance apócrifo ou marginal. In: SIMPÓSIO DE ESTUDOS CLÁSSICOS DA USP, 3. São Paulo: Humanitas, 2009, p. 59-78.

IPIRANGA JÚNIOR; Pedro, DUARTE; Adriane. As recensões G e W da Vida de Esopo. Classica, v. 27, n. 2, p. 293-316, 2014. DOI: https://doi.org/10.24277/classica.v27i2.322

JOUANNO, Corinne. Novelistic lives and historical biographies: The Life of Aesop and the Alexander Romance as fringe novels. In: KARLA, Grammatiki A. (ed.). Fiction on the fringe: novelistic writing in the post-classical age. Leiden: Bril, 2009, p. 33-48.

JOUANNO, Corinne. Vie d'Ésope. Traduite et commentée par Corinne Jouanno. Paris: La Roue à Livres, 2006. 
KARLA, Grammatiki A. Fictional biography vis-à-vis romance: Affinity and differentiation. In: KARLA, Grammatiki A. (ed.). Fiction on the fringe: novelistic writing in the post-classical age. Leiden: Brill, 2009, p. 13-32.

KARLA, Grammatiki A. Folk narrative techniques in the "Alexander Romance". Mnemosyne, v. 65, p. 636-65, 2012.

KONSTANTAKOS, Ioannis. The magical transformation contest in the ancient storytelling tradition. CFC (g): Estudios griegos e indoeuropeos, v. 26, p. 207-34, 2016.

KOULAKIOTIS, Ilias. Plutarch's Alexander, Dionysos and the metaphysics of power. In: HOWE, Timothy; MÜLLER, Sabine; STONEMAN, Richard (ed.). Ancient historiograpby on war and empire. Oxford: Oxbow Books, 2017, p. 226-49.

LONG, H. S. (ed.). Diogenis Laertii vitae philosophorum. Oxford: Clarendon Press, $1966^{2} .2$ v. 1966.

LUCIANO. Obras. Traducción y notas por J. Alsina. Madrid: Gredos, 1981. v. 1.

LUCIANO. Obras. Traducción y notas por J. L. N. González. Madrid: Gredos, 1988. v. 2.

LUCIEN. Oeuvres. Introdução de J. Bompaire. Paris: Les Belles Lettres, 1993.

MAITLAND, Judith. MHNIN AEI $\triangle \mathrm{E}$ @EA: Alexander the Great and the anger of Achilles. In: WHEATLEY, Pat; BAYHAM, Elizabeth (ed.). East and West in the world empire of Alexander. Essays in honor of Brian Bosworth. Oxford: Oxford University Press, 2015, p. 1-20.

MHEALLAIGH, Karen Ní. Pseudo-documentarism and the limits of Ancient Fiction. American Journal of Philology, v. 129, n. 8, p. 403-33, Fall 2001. Disponível em: http:/ / muse.jhu. edu/journals/ajp/summary/v129/129.3.mheallaigh.html. Acesso em: 4 out. 2014.

MOMIGLIANO, Arnaldo. De paganos, judíos y cristianos. México: Fondo de Cultura Económica, 1992.

MOMIGLIANO, Arnaldo. La naissance de la biographie en Grèce ancienne. Traduit de l'anglais par Estelle Oudot. Strausbourg: Circé, 1991.

NAWOTKA, Krzysztof. The Alexander Romance by Ps.-Callisthenes: a bistorical commentary. Leiden: Brill, 2017.

PAPATHOMOPOULOS, Manoles. Ho bios tou Aisopou. Heparallage W. Editio princeps. Athens: Ekdoseis Papadema, 1999.

PHILOSTRATUS; EUNAPIUS. Lives of the sophists, Lives of philosophers. Translation by Wilmer Cave Wright. Cambridge, MA: Harvard University Press, 1989.

PHILOSTRATUS. The Life of Apollonius of Tyana. Ed. Christopher P. Jones. Cambridge, MA: Harvard University Press, 2005. 2. v. (Loeb Classical Library, 16, 17). 
POLO, Francisco Pina. El periplo del mar eritreo y la presencia romana en índico. In: PINA, Francisco Marco et al. (ed.) Viajeros, peregrinos y aventureros en el mundo antiguo. Barcelona: Publicacions i Edicions Universitat de Barcelona, 2010, p. 101-14.

PUECH, B. Orateurs et sophistes Grecs dans les inscriptions d'époque impériale. Paris: Vrin, 2002.

RABELO, Laura Cohen. Vida e feitos de Alexandre da Macedônia: tradução e comentário de um romance de Alexandre grego. Dissertação (Mestrado em Estudos Literários) - Programa de Pós-graduação em Estudos Literários da Faculdade de Letras, Universidade Federal de Minas Gerais, Belo Horizonte, 2017.

SCHIRREN, Thomas. Irony versus eulogy. The Vita Apolonii as metabiographical fiction. In: DEMOEN, Kristoffel; PRAET, Danny (ed.). Theios sophistes. Leiden: Brill, 2009, p. 161-86.

SILVA, Semíramis Corsi. O Império Romano do sofista grego Filóstrato nas viagens da Vida de Apolônio de Tiana (século III d.C.). Tese (Doutorado em História) - Programa de PósGraduação em História da Faculdade de Ciências Humanas e Sociais, Universidade Estadual Paulista. Franca, 2014.

STONEMAN, Richard (ed.). Il Romanzo di Alessandro. Traduzione di Tristano Gargiulo. Milano: Fondazione Lorenzo Valla; A. Mondadori, 2007. v. 1.

TILG, Stephan. Chariton of Aphrodisias and the invention of the Greek love novel. Oxford: Oxford University Press, 2010.

VAN UYTANGHE, Marc. La Vie d'Apollonius de Tyane et le discour hagiographique. In: DEMOEN, Kristoffel; PRAET, Danny (ed.). Theios sophistes. Leiden: Brill, 2009, p. 335-74.

WATSON, Gerard. The concept of 'phantasia' from the late hellenistic period to early neoplatonism. Aufstieg und Niedergang der Römischen Welt, v. 36, n. 7, p. 4765-810, 1994.

WHEATLEY, Pat; BAYHAM, Elizabeth (ed.). East and West in the world empire of Alexander. Essays in honor of Brian Bosworth. Oxford: Oxford University Press, 2015. 